\title{
PENERAPAN DATA MINING DENGAN METODE ALGORITMA APRIORI UNTUK MENENTUKAN POLA PEMBELIAN IKAN
}

\author{
Saefudin, M.Kom ${ }^{1}$, Septian $\mathrm{DN}^{2}$, \\ ${ }^{1,2}$ Program Studi Sistem Informasi Fakultas Teknologi Informasi \\ Universitas Serang Raya \\ ${ }^{1}$ Saefudin12@gmail.com, \\ ${ }^{2}$ Septian@gmail.com
}

\begin{abstract}
Abstrak - Tujuan pembuatan aplikasi data mining menggunakan metode Algoritma apriori adalah untuk menentukaan pola pembelian jenis ikan yang paling diminati pada UD. Mumu Jaya. UD. Mumu Jaya Pandeglang adalah usaha dagang yang bergerak di bidang penjualan ikan laut di pasar pandeglang. UD. Mumu Jaya merupakan suatu jenis usaha penjualan ikan laut untuk menentukan ikan yang akan dibeli untuk persediaan gudang. Saat ini semua kegiatan transaksi yang berhubungan dengan penjualan dan pembelian masih mengunakan buku catatan seperti untuk pendataan ikan, pendataan penjualan ikan, dan masih memperkirakan ikan yang akan dibeli untuk memenuhi persediaan ikan pada gudang, selain itu masih belum adanya model perhitungan untuk menentukan belanja persediaan ikan yang paling diminati oleh konsumen. Untuk mendukung kegiatan tersebut maka perlu dibuat aplikasi yang dapat membantu permasalah tesebut, yakni dengan dibuatnya suatu aplikasi data mining menggunakan metode Algoritma apriori untuk menentukaan jenis ikan yang paling diminati oleh konsumen.
\end{abstract}

Kata Kunci : Data Mining, Algoritma Apriori, Penjualan Ikan

\section{PENDAHULUAN}

Perusahaan dapat memanfaatkan data yang dihasilkan oleh sistem informasi yang digunakan untuk membantu dalam pengambilan keputusan jika diolah dengan benar, data-data tersebut dapat menghasilkan informasi. Pemanfaatan data yang ada di dalam sistem informasi untuk menunjang kegiatan pengambilan keputusan tidak cukup hanya mengandalkan data operasional saja, diperlukan suatu analisis data untuk menggali potensi informasi yang ada. Memanfaatkan gudang data yang sudah dimiliki untuk menggali informasi yang berguna membantu mengambil keputusan, hal ini mendorong munculnya cabang ilmu untuk mengatasi masalah penggalian informasi atau pola yang penting atau menarik dari data dalam jumlah besar, yang disebut dengan Data mining. Penggunaan teknik Data mining diharapkan dapat memberikan pengetahuan yang sebelumnya tersembunyi di dalam gudang data sehingga menjadi informasi yang berharga.Salah satu bentukpola yang dapat dihasilkan Data mining adalah AlgoritmaApriori. Algoritma Apriori adalah salah satu algoritma yang melakukan pencarian frequent itemset dengan menggunakan teknik association rule (Erwin,2009).

UD. Mumu Jaya Pandeglang adalah usaha dagang yang bergerak di bidang penjualan ikan di pasar pandeglang,didirikan sejak tahun 1990 oleh bapak H. Masud dan diteruskan oleh anaknya yaitu bapak Mumu, saat ini UD. Mumu Jaya Pandeglang telah menjadi distributor ikan laut di pasar pandeglang. UD. Mumu Jaya Pandeglang memiliki gudang, gudang ini berfungsi untuk menyimpan stok berbagai macam ikan yang akan dijual, melihat pada gudang UD. Mumu jaya Pandeglang masih mengunakan buku catatan untuk pendataan ikan, pendataan penjualan ikan, dan masih memperkirakan ikan yang akan dibeli untuk memenuhi persediaan ikan pada gudang, selain itu masih belum adanya model perhitungan untuk menentukan belanja persediaan ikan yang paling diminati oleh konsumen, sehingga terjadi penumpukan ikan yang kurang laku di gudang dan akan menyebabkan kerugian.

Untuk itu dibutuhkan aplikasi yang mendukung penyelesaian masalah tesebut, yakni dengan aplikasi data 
mining menggunakan metode algoritma apriori untuk menentukaan ikan yang paling diminati oleh konsumen, sehingga memudahkan UD. Mumu Jaya Pandeglang untuk menentukan ikan yang akan dibeli untuk persediaan gudang.

\subsection{Data Mining}

\section{METODOLOGI PENELITIAN}

Data mining adalah sebuah proses percarian secara otomatis informasi yang berguna dalam tempat penyimpanan data berukuran besar. Tahapan data mining adalah :

a) Data Cleaning (untuk menghilangkan noise data yang tidak konsisten)

b) Data Integration (dimana sumber data yang terpecah dapat disatukan).

c) Data selection (di mana data yang relevan dengan tugas analisis dikembalikan ke dalam database).

d) Data transformation (di mana data berubah atau bersatu menjadi bentuk yang tepat untuk menambang dengan ringkasan performa atau operasi agresi).

e) Data mining (proses esensial di mana metode yang intelijen digunakan untuk mengekstrak pola data).

f) Pattern evolution (untuk mengidentifikasi pola yang benar-benar menarik yang mewakili pengetahuan berdasarkan atas beberapa tindakan yang menarik).

g) Knowledge presentation (di mana gambaran teknik visualisasi dan pe-ngetahuan digunakan untuk memberikan pengetahuan yang telah ditam-bang kepada user).

\subsection{Algoritma Apriori}

Algoritma Apriori adalah salah satu algoritma yang melakukan pencarian frequensi itemset dengan menggunakan teknik association rule. Algoritma Apriori menggunakan pengetahuan frekuensi atribut yang telah diketahui sebelumnya untuk memproses informasi selanjutnya. Pada algoritmaApriori menentukan kandidat yang mungkin muncul dengan cara memperhatikan minimum support dan minimum confidence. Support adalah nilai pengunjung atau persentase kombinasi sebuah item dalam database. (Erwin,2009).

2.3 Delphi

Delphi adalah bahasa pemograman terstruktur yang dibuat dengan basis Visual/ Grafik windows, dan merupakan versi lanjuatan dari Turbo Pascal. Delphi merupakan bahasa pemograman yang mempunyai cakupan kemampuan yang luas.(M.Alam, Agus, 2011).

2.4 MySQL

$M y S Q L$ adalah program database yang mampu mengirim dan menerima data dengan sangat cepat dan multi user. MySQL memiliki dua bentuk lisensi, yaitu free software dan shareware.

\section{HASIL DAN PEMBAHASAN}

3.1 Analisis Pola Frekuensi Tinggi Dengan Algoritma
Apriori

Tahap ini mencari kombinasi item yang memenuhi syarat minimum dari nilai support dalam basisdata. Nilai support sebuah item diperoleh dengan menggunakan rumus sebagai berikut :

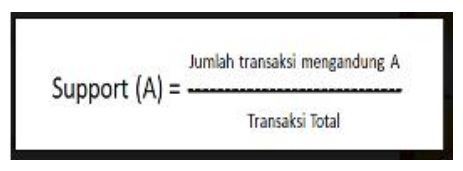

Gambar 1 Rumus kombinasi item

- Untuk mencari nilai support dari 2 item diperoleh i rumus 2 berikut:

- $\operatorname{Support}(\mathrm{A}, \mathrm{B})=\mathrm{P}(\mathrm{A} \cap \mathrm{B})$

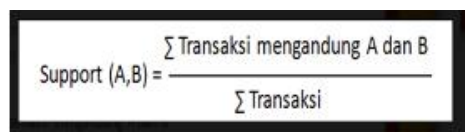

Gambar 2 Rumus nilai suport

Setelah semua pola frekuensi tinggi ditemukan, barulah dicari aturan asosiasi yang memenuhi syarat minimum untuk confidence dengan menghitung confidence aturan asosiatif A B Nilai confidence dari aturan A B diperoleh dengan rumus berikut ini :

$$
\begin{aligned}
& C=P(B \mid A)
\end{aligned}
$$

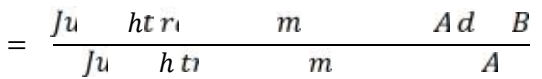

Untuk menentukan aturan asosiasi yang akan dipilih maka harus diurutkan berdasarkan Support $\times$ Confidence. Aturan diambi lsebanyak $\mathrm{n}$ aturan yang memiliki hasil terbesar. Tabel 3.1 dibawah ini merupakan transaksi penjualan UD. Mumu Jaya Pandeglang selama 1 minggu.

Tabel 1 Data Transaksi

\begin{tabular}{|l|l|l|}
\multicolumn{2}{|c|}{ Tabel 1 Data Transaksi } \\
\hline No & Nama & Nama ikan \\
\hline 2 & Transaksi 1 & Salem K, layang \\
\hline 3 & Transaksi 2 & Bentong B, layang, bentong K \\
\hline 4 & Transaksi 3 & Bentong B, layang, salem K \\
\hline 5 & Transaksi 4 & Bandeng, tongkol, salem K, tuna \\
\hline 6 & Transaksi 5 & Bandeng, salem K \\
\hline 7 & Transaksi 7 & Bentong B, layang, salem K, salem B \\
\hline 8 & Transaksi 8 & Bandeng, bentong K, layang,salem K \\
\hline 9 & Transaksi 9 & Layang,salem K, bentong K \\
\hline 10 & Transaksi10 & Salem K, salem B, bandeng \\
\hline 11 & Transaksi 11 & Bentong B, layang, salem K, salem B \\
\hline 12 & Transaksi 12 & Bentong B, layang, salem K, salem B \\
\hline 13 & Transaksi 13 & Bandeng, salem K, bentong K \\
\hline
\end{tabular}




\begin{tabular}{|l|l|l|}
\hline 14 & Transaksi 14 & Bandeng, tongkol, layang, bentong K \\
\hline 15 & Transaksi 15 & Bentong B, salem K, salem B \\
\hline 16 & Transaksi 16 & Bentong B, salem K, salem B \\
\hline 17 & Transaksi 17 & Bandeng, tongkol, salem K \\
\hline 18 & Transaksi 18 & Bandeng, salem K, tongkol \\
\hline 19 & Transaksi 19 & Bentong B, bentong K, salem K \\
\hline 20 & Transaksi 20 & Bentong B, bentong K, salem K \\
\hline 21 & Transaksi 21 & Salem K, bentong K, layang \\
\hline 22 & Transaksi 22 & Salem K, salem B, bandeng \\
\hline 23 & Transaksi 23 & Bandeng, tongkol, tuna \\
\hline 24 & Transaksi 24 & Bandeng, tuna, salem K \\
\hline 25 & Transaksi 25 & Bentong K, layang, kurisi \\
\hline 26 & Transaksi 26 & Bentong B, layang, salem B \\
\hline 27 & Transaksi 27 & Tuna, tongkol, bandeng \\
\hline 28 & Transaksi 28 & Bandeng, tongkol, salem K \\
\hline 29 & Transaksi 29 & Bandeng, tongkol, tuna \\
\hline 30 & Transaksi 30 & Bandeng, salem K, kurisi \\
\hline 31 & Transaksi 31 & Bentong B, bentong K, salem K \\
\hline 32 & Transaksi 32 & Bentong B, bentong K, layang \\
\hline 33 & Transaksi 33 & Bandeng, tongkol, kurisi \\
\hline & & \\
\hline
\end{tabular}

Berikut adalah penyelesaian berdasarkan data yang sudah disediakan pada tabel 3.1, proses pembentukan 1itemset dengan jumlah minimum support $=10$.

Tabel 2 tabel 1-itemset

\begin{tabular}{|c|l|c|}
\hline NO & \multicolumn{1}{|c|}{ Itemset } & Support \\
\hline 1 & Salem K & 24 \\
\hline 2 & Salem B & 9 \\
\hline 3 & Bentong B & 13 \\
\hline 4 & Bentong K & 11 \\
\hline 5 & Layang & 14 \\
\hline 6 & Bandeng & 16 \\
\hline 7 & Tongkol & 9 \\
\hline 8 & Tuna & 5 \\
\hline 9 & Kurisi & 3 \\
\hline
\end{tabular}

Dari tabel 3.2 diatas kita bisa mengetahui item apa sajakah yang memiliki minimum support yang telah kita tentukan sebelumnya yaitu support $=10$. Item-item yang memenuhi minimum support di sebut frequent 1 -itemset. Daftar frequent 1-itemset dapat kita lihat di tabel berikut.

Tabel 3 Tabel frequent 1-itemset

\begin{tabular}{|c|l|c|}
\hline NO & Itemset & Support \\
\hline 1 & Salem K & 24 \\
\hline 2 & Bentong B & 13 \\
\hline 3 & Bentong K & 11 \\
\hline 4 & Layang & 14 \\
\hline 5 & Bandeng & 16 \\
\hline
\end{tabular}

Dari daftar frequent 1-itemset pada tabel 3.3 di atas di buat menjadi daftar calon frequent 2-itemset, maka akan di dapatkan hasil seperti pada tabel 3.3 berikut.

Tabel 4 2-itemset

\begin{tabular}{|c|l|c|}
\hline NO & Itemset & Support \\
\hline 1 & Salem K, bentong B & 10 \\
\hline 2 & Salem K, bentong K & 7 \\
\hline 3 & Salem K, layang & 9 \\
\hline 4 & Salem K, bandeng & 11 \\
\hline 5 & Bentong B, bentong K & 5 \\
\hline 6 & Bentong B, layang & 8 \\
\hline 7 & Bentong B, bandeng & 0 \\
\hline 8 & Bentong K, layang & 7 \\
\hline 9 & Bentong K, bandeng & 3 \\
\hline 10 & Layang, bandeng & 2 \\
\hline
\end{tabular}

Dari tabel 3.4 frequent 2-itemset di atas bahwa yang berhak menjadi frequent 3 -itemset seperti yang bisa di lihat di tabel 3.5 berikut

Tabel 5frequent 2-itemset

\begin{tabular}{|l|l|c|}
\hline No & \multicolumn{1}{|c|}{ Itemset } & Support \\
\hline 1 & Salem K, Bentong B & 10 \\
\hline 2 & Salem K, Bandeng & 11 \\
\hline
\end{tabular}

Setelah itu kita hitung nilai Support dan Confidence dari masing-masing frequent itemset.

Tabel 6 Support

\begin{tabular}{|l|l|c|}
\hline No & Itemset & Support \\
\hline 1 & Salem K, Bentong B & $30 \%$ \\
\hline 2 & Bentong B, Salem K & $30 \%$ \\
\hline 3 & Salem K, Bandeng & $33 \%$ \\
\hline 4 & Bandeng, Salem K & $33 \%$ \\
\hline
\end{tabular}

Tabel 7 Confidence

\begin{tabular}{|c|c|c|c|c|c|c|}
\hline $\mathrm{N}$ & \multicolumn{2}{|l|}{ Itemset } & $\begin{array}{l}\text { Aturan } \\
\text { asosiasi }\end{array}$ & \multirow{2}{*}{$\begin{array}{l}\text { support } \\
30 \%\end{array}$} & \multicolumn{2}{|c|}{ Confidence } \\
\hline 1 & $\begin{array}{l}\text { Salem } \\
\text { bentong B }\end{array}$ & $\mathrm{K}$, & $\begin{array}{l}\text { jika beli } \\
\text { ikan salem } \\
\text { K maka beli } \\
\text { ikan } \\
\text { bentong B }\end{array}$ & & $\frac{10}{24}$ & $41 \%$ \\
\hline 2 & $\begin{array}{l}\text { Bentong } \\
\text { Salem K }\end{array}$ & $\mathrm{B}$, & $\begin{array}{lr}\text { jika } & \text { beli } \\
\text { ikan } & \\
\text { bentong } & \mathrm{B} \\
\text { maka } & \text { beli } \\
\text { ikan ralem } \\
\text { K }\end{array}$ & $30 \%$ & $\frac{10}{24}$ & $41 \%$ \\
\hline 3 & $\begin{array}{l}\text { Salem } \\
\text { bandeng }\end{array}$ & $\mathrm{K}$, & $\begin{array}{rr}\text { jika } & \text { beli } \\
\text { ikan } & \text { Salem }\end{array}$ & $33 \%$ & $\frac{11}{24}$ & $45 \%$ \\
\hline
\end{tabular}




\begin{tabular}{|l|l|l|l|l|l|}
\hline & & $\begin{array}{l}\text { K maka beli } \\
\text { ikan } \\
\text { Bandeng }\end{array}$ & & & \\
\hline 4 & $\begin{array}{l}\text { Bandeng, salem } \\
\text { K }\end{array}$ & $\begin{array}{l}\text { jika beli } \\
\text { ikan } \\
\text { Bandeng } \\
\text { maka beli } \\
\text { ikan salem } \\
\text { K }\end{array}$ & & $\frac{11}{24}$ & $45 \%$ \\
\hline
\end{tabular}

Untu kmenentukan aturan asosiasi yang akan dipilih maka harus diurutkan berdasarkan Support $\times$ Confidence. Aturan diambil sebanyak $\mathrm{n}$ aturan yang memiliki hasil terbesar.

Tabel 8 Support x Confidence

\begin{tabular}{|l|l|c|}
\hline No & Itemset & $\begin{array}{l}\text { Support } \mathrm{x} \\
\text { Confidence }\end{array}$ \\
\hline 1 & Salem K, bentong B & $12 \%$ \\
\hline 2 & Bentong B, Salem K & $12 \%$ \\
\hline 3 & Salem K, bandeng & $14 \%$ \\
\hline 4 & Bandeng, salem K & $14 \%$ \\
\hline
\end{tabular}

\section{PERANCANGAN SISTEM}

Perancangan sistem adalah suatu kegiatan perancangan atau design sebelum aplikasi dibuat dan merupakan tahapan setelah analisa sistem.

\subsection{Usecase Diagram}

Use case diagram menggambarkan fungsionalitas yang diharapkan dari sebuah sistem.



Gambar 3 Diagram use case

\subsection{Class Diagram}

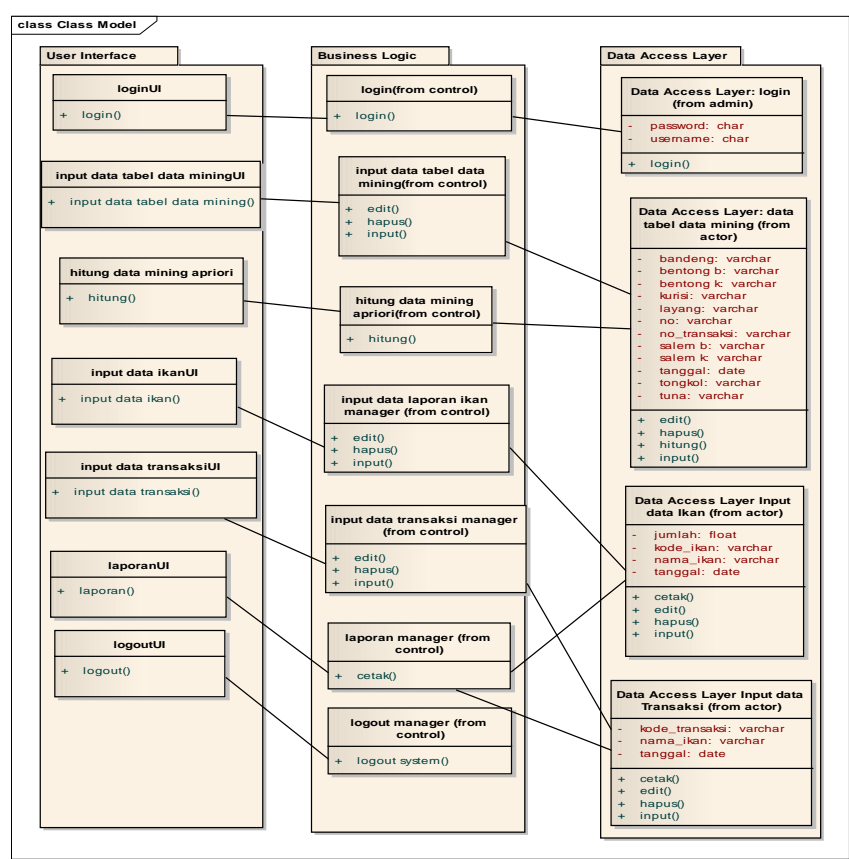

Gambar 4 Class Diagram

\section{IMPLEMENTASI SISTEM}

\subsection{Halaman Menu Utama}

Halaman utama merupakan form yang berfungsi untuk mengakses halamanhalaman atau form yang terdapat dalam aplikasi. Halaman ini akan tampil ketika admin telah berhasil login maka admin dapat mengakses halaman yang ada sesuai kebutuhan.

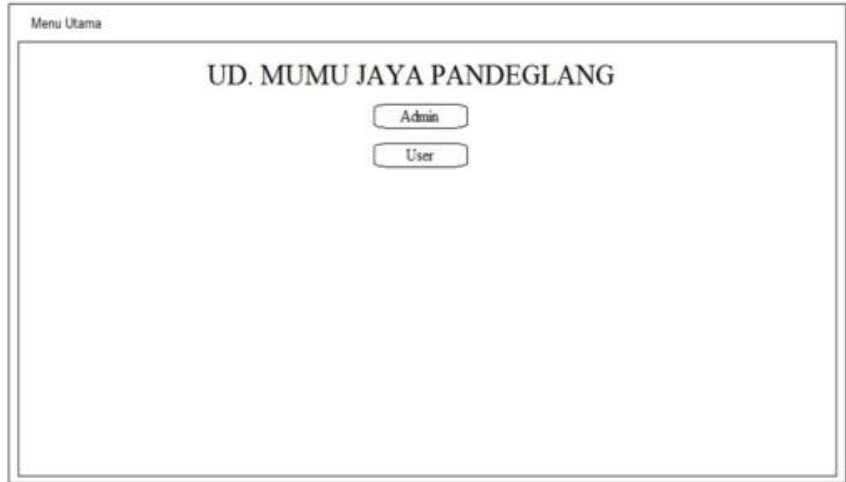

Gambar 5 Halaman Menu Utama 


\subsection{Halaman Data Mining}

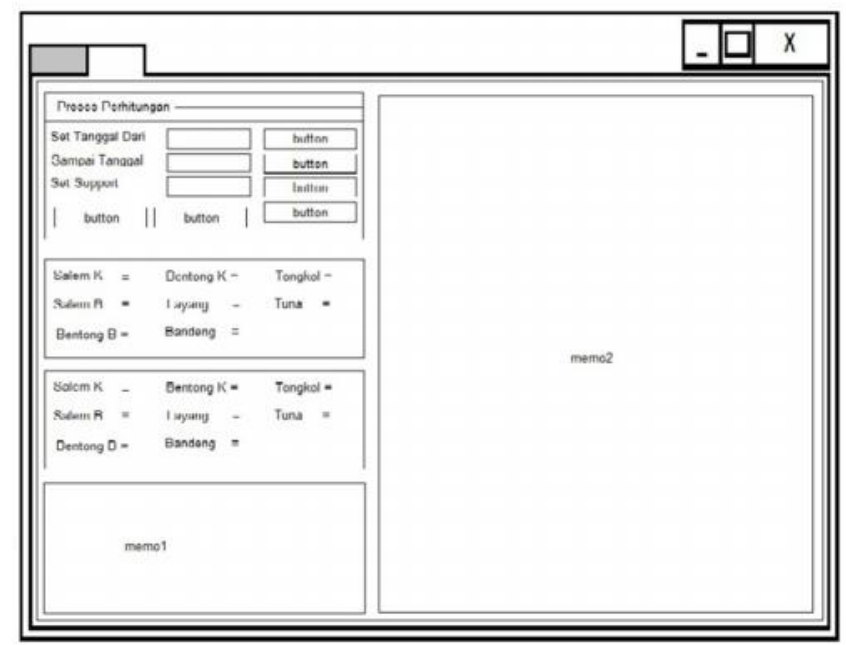

Gambar 6 Halaman Data Mining

\section{KESIMPULAN}

Dari hasil pembahasan, perancangan dan implementasi yang telah dilakukan dalam penelitian dapat disimpulkan bahwa :

1. Aplikasi Data Mining untuk menentukan jenis ikan paling diminati dengan menggunakan metode algoritma apriori Pada UD. Mumu Jaya Pandeglang dirancang dengan permodelan UML (UnifiedModelingLanguage) dibuat dengan menggunakan Borland Delphi 7 dan Database menggunakan MySQL. Aplikasi ini membantu UD. Mumu Jaya Pandeglang dalam menentukan jenis ikan yang paling diminati oleh konsumen, pendataan data transaksi dan data stok ikan.

2. Aplikasi Data Mining Untuk Menentukan Jenis Ikan Paling Diminati Dengan Menggunakan Metode Algoritma Apriori di implentasikan kepada UD. Mumu Jaya Pandeglang untuk mengetahui jenis ikan paling diminati, mendata transaksi, dan mendata stok ikan.

\section{REFERENSI}

[1] Indriyawan, Eko., Francisca Aure Liasie., Tomi Sayugo. (2011). Mastering Delphi XE. Yogyakarta : Andi Offset.

[2] Kadir, Abdul. (2010). Mudah Mempelajari Database MySQL. Yogyakarta : Andi Offset.

[3] Kusrini., Emha Taufiq Luthfi. (2009). Algoritma Data Mining. Yogyakarta: Andi Offset.

[4] Rosa A.S. M.Shalahuddin. :(2013) Rekayasa Perangkat Lunak. Bandung: Informatika Bandung.
[5] Tampubolon, Kennedi., Hoga Saragih., Bobby Reza. (2013). Implementasi Data Mining Algoritma Apriodi Pada Sistem Persediaan Alat-alat Kesehatan. 